the same is true too of spontaneous abortion rates, and the supposition is borne out by the only authoritative study known to me on this topic. ${ }^{3}$ So the disparity (suggested above) in the data of Dr. Roberts and Mrs. Lloyd exists in spite of, not because of social clas differences between the areas. (2) Dr. Roberts and Mrs. Lloyd show that if there is deficit in reporting of abortions in area $A$ it seems not to be dependent on social class However, (a) their technique of controlling for social class is very coarse (they use only two social class categories, manual and nonmanual) and as such could not be expected to eliminate class differences within the categories, and (b) this suspected reporting deficit may be dependent on factors other than social class.

Dr. Roberts and Mrs. Lloyd are committed to rejecting the alternative of this reporting deficit; they seem, therefore, to be saddled with the difficulty of explaining why non-A.S.B. spontaneous abortions (like A.S.B. spontaneous abortions) are less common in area A than area B. However, it is perhaps not appropriate to devote too much a priori argument to their hypothesis After all, it is testable. I suggest that samples of spontaneously aborted fetuses in the two areas be examined. If the hypothesis is correct, there should be a higher proportion of A.S.B. fetuses in the low-risk area.-I am, etc.,

W. H. JAMES

Department of Human Genetics and Biome:ry, University College,

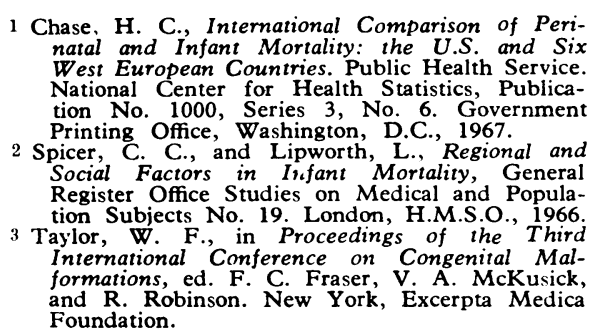

\section{Oxygen Therapy}

SIR,-In their article entitled "Oxygen Therapy in Chronic Respiratory Failure" (20 October, p. 154) Dr. R. Hume and others state that the M.C. mask "normally delivers about $60 \%$ oxygen." This bald statement while ostensibly being covered by the words "normally" and "about," may give a false impression of accuracy to an uncritical reader who may subsequently have occasion to use the mask. The figure of $60 \%$ will then spring to mind unaccompanied by any conditions or reservations.

Devices of this kind have such a highly variable performance that it is importan when referring to them to leave no doubt about the accuracy and variability of the resulting inspired oxygen concentration and the conditions affecting it. The only conditions which are easy to define are the flow rate of oxygen and the respiratory frequency. Unfortunately, these are usually less important than the tidal volume, the inspiratory flow rate, and the shape of the patient's face in relation to the mask. Moreover because of the small volume of the mask there is, during the course of one breath, a highly variable inspired oxygen concentration. The mean $\mathrm{PaO}_{2}$ thus produced is not necessarily the same as would be produced by the inhalation of a constant mixture of the same concentration as the so-called "mean" from the M.C. mask.

These masks are not suitable for the administration of accurate concentrations of oxygen and it is submitted that in the context of this article it would have been better to talk only in terms of the $\mathrm{PaO}_{2}$ that the device produced in a particular patient at a particular time than to quote unreliable figures for inspired oxygen concentrations. -I am, etc.

Brompton Hospital,

A. M. HewLETT London S.W.3

\section{Treatment of Depression in General Practice}

SIR,-The results and comments of Dr. D. A. W. Johnson in his paper on the treatment of depression in general practice (7 April, p. 18) seemed so different from our own experience that we were prompted to extract some figures of our own depressed patients.

Part of our practice is urban and based on Woodside Health Centre, Glasgow. We extracted information retrospectively from all patients diagnosed as depressed in our Woodside practice (3,400 patients) attending over a four-month period. This was easy to do as we use a system of morbidity and workload recording based on feature cards. The relevant results are as follows:

\begin{tabular}{|c|c|c|}
\hline & Our results & $\begin{array}{l}\text { Dr. Johnson's } \\
\text { results }\end{array}$ \\
\hline 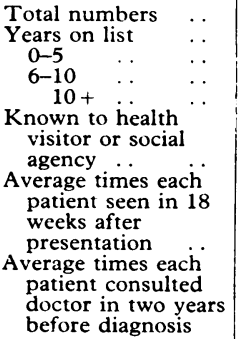 & $\begin{array}{l}66 \\
20 \% \\
17 \% \\
62 \% \\
20 \% \\
4.7\end{array}$ & $\begin{array}{l}50 \% \\
25 \% \\
25 \% \\
0 \% \\
0 \%\end{array}$ \\
\hline
\end{tabular}

Our figures thus differ significantly from Dr. Johnson's. With the average depressed patient having been on our list for 17 years and having consulted us 16 times in the past two years we can fairly be said to be likely to have a knowledge of the patient and his background. We do not claim that our practice is a typical one, but neither had Dr. Johnson any reason to claim that the practices he selected were typical. Further the depressed patients he selected were only those who had had no symptoms or psychotropic medication for the year before the present attack.

From a small group of selected patients studied under abnormal circumstances from selected practices, all apparently in one city in Britain, Dr. Johnson draws conclusions about all depressed patients managed in any city in Britain. This is an unjustified extension of his findings. Our own findings show that they are certainly not universally applicable.-We are, etc.,

KENNETH HARDEN W. THORBURN

R. T. W. PRENTICE DIANA KIERNAN

\section{Scotland's Drink Problem}

SIR,-Licensing laws are said by both the Erroll Committee in England ${ }^{1}$ and the Clayson Committee in Scotland, ${ }^{2}$ referred to in your leading article (13 October, p. 64) to play a minor part only in the control of alcohol misuse. Both rightly stress the great importance of education and researchthough one wonders why such research into the gaps of knowledge should not be undertaken before any of the proposed changes in legislation. At any rate, it has certainly not been proved that restrictive legislation-for example, the limitation of opening hoursis of no avail. In fact, the change in England from a situation of widespread drunkenness to relative sobriety took place fairly suddenly during the 1914-18 war $^{3}$-in the views of many observers mainly as a consequence of the recommendations of the Liquor Control Board. 4-6 In the view of G. B. Wilson ${ }^{3}$ the remarkable improvement was brought about by direct restrictions on the supply of liquor, by the administrative restriction on hours of sale, by dilution of beers and spirits, etc.; and he felt that "particularly since 1913 .. later hours of opening, the midday break, and earlier closing hours have been very important factors .... in checking a rise in the aggregate consumption ... and possibly in checking individual consumption." Similarly, Shadwell felt that among state control measures "shorter hours and higher taxation ... have proved really efficaceous." Most of the recent work in this field has been carried out by the Addiction Research Foundation in Ontario; they regard the price of alcohol in relation to disposable income as the most important factor in influencing alcohol consumption, and they feel that the area of control of days and hours of sale deserves further research.?

Clearly, as Erroll points out, other factors (for example, counterattractions, increasing afuence, etc.) contributed to the decrease of the drink problem in the first half of the twentieth century. ${ }^{3}$ Such factors, however, also affected other nations, none of which (as far as I am aware) showed the remarkable sudden drop in drunkenness. Rather than for this country to follow the "civilized" drinking of Continental countries one wonders whether it might not be a better idea for such countries-most of them with far larger alcohol problems (as yet?) than Britain-to study the conditions and methods used in this country. It is well known, for example, how far the alcoholism problem in France with all its "civilized" drinking habits outstrips the British problem.

To what extent the changes recommended by Erroll and Clayson will increase alcohol consumption or otherwise is of course $n$ t known. They certainly will increase availability, and health-related alcohol and drug problems may stem not only from individual ("host") susceptibility but also from availability of the "agent" (alcohol or other drugs). ${ }^{8}$ Recent research in Ontario has confirmed earlier findings ${ }^{9}$ of a relationship between a nation's per capita alcohol consumption and the prevalence of alcoholrelated damage and complications. ${ }^{8} 10$ In his recent talk to the 1973 conference of the Medical Council on Alcoholism, De Lint ${ }^{10}$ pointed to the evidence that the current world-wide trends in excessive alcohol use and alcohol-related mortality followed a growing acceptance of alcohol use in every- 